British medical and scientific men is indicated by "Medicus M.P. in France" (Lancet, June 1, p. 1031), who speaks of the constant consultations taking place between medical officers of divisions of the two forces and the meetings of French and British consultants, including distinguished civilians, at G.H.Q., at which views are exchanged, leading with numerous other facilities to a far greater degree of co-operation than during 1914-18. This readiness to co-operate and unity of purpose, it may be anticipated with no little confidence, will inspire the co-operation in Colonial administration in the future upon which the two Governments have agreed. Now that the resources of the Belgian Congo and Mandated Territory, upon which the Belgian Government has lavished expenditure, have been placed at the disposal of Belgium's allies, a valuable opportunity has arisen for laying the foundations of future research and co-ordinated action.

\section{Blood-Group Tests and Paternity}

IN view of the application of blood-group tests in medico-legal problems involving disputed bloodrelationship, it is interesting to note results of the test in a series of fifty cases which have been recorded by Dr. David Harley and Dr. G. Roche Lynch (Lancet, May 18, 1940). Most of the cases were affiliation cases; in these, as is well known, the blood test, while not establishing paternity, does eliminate false accusation by establishing non-paternity, the expected rate of establishment on the assumption that all men are falsely accused being approximately 32 per cent. In the present series, non-paternity was established in eight cases, or 16 per cent, a figure which suggests that about half the men were falsely accused, while half were in fact the fathers. The authors point out that while the percentage is not likely to be so high in the 5,000 affiliation cases heard in England and Wales in the course of a year, since in many of them paternity is not in dispute, but merely the amount of compensation, yet the fact that an appreciable number of men prefer to go to prison rather than pay suggests that the number of false accusations is by no means negligible. With improvement in the technique of identifying subgroups, the utilization of these factors should add to the value of the test in such proceedings by raising the percentage of exclusions possible.

\section{National Collections in London or in the Country?}

A MATTER of very great importance to scientific workers in Great Britain and throughout the world is raised by Dr. Percy $R$. Lowe in an article discussing the threatened removal of the ornithological collections from the British Museum (Natural History) to Tring (Museums $J ., 49$; May 1940). It is there stated that "the Trustees of the Museum seriously contemplate transferring the national ornithological collections from South Kensington in London to Tring in Hertfordshire". That would indeed be a serious step, for no expert studies bird skins without using the books referring to the group upon which he is working. So that the ornithological library would have to follow. But many bird papers appear in journals not specifically devoted to ornithology; would the series of these journals also have to go, or would the expert be left in the lurch ? That seems to be a problem not easily solved; Dr. Lowe discusses others. But indeed the proposal bristles with so many difficulties that it may be taken for granted that the Trustees will seek advice from scientific workers who are accustomed to study ornithological or other systematic collections, and will make no decision even for the future without the fullest inquiry and consultation.

\section{The British Pharmacopœia : Emergency Monographs}

THE need for an addendum to the "British Pharmacopœia" which is now ready for official publication was dictated by war-time circumstances which deprived. Great Britain of unfettered access to supplies of cod liver oil and olive oil and made it desirable to sanction the use of substitutes for both. The outstanding new monograph in the Addendum is on oleum vitaminatum, a vitaminized oil which is a solution of vitamins A and D containing 1,000 units of vitamin A activity and 100 units of antirachitic activity (vitamin D) in $1 \mathrm{gm}$. It is clear that the object of the Pharmacopoia Commission was to provide a standard for a substitute for cod liver oil which, in respect of its vitamin contents, should approximate to the natural product. The vehicle for the vitamins may be "a suitable vegetable oil" the choice of which is left to the manufacturer, with the suggestion that arachis oil would answer the purpose at least as well as any other. Provided the preparation responds to the characters and tests for purity laid down in the monograph, vitaminized oil may consist, alternatively, of a suitable fish-liver oil, or blend of fish-liver oils, thus allowing to commercial firms a generous latitude which is justifiable, and indeed advisable, in a time of emergency. Of the nine other new monographs in the Addendum, seven are related to the cod liver oil problem; they include standards for concentrated solutions of vitamins and for emulsions of cod liver oil itself and its substitute.

The only new monograph which is unrelated to cod liver oil is that on tetanus toxoid, which is officially described as "tetanus toxin, the sterile filtrate of a culture on a suitable medium of Clustridium tetani, or material derived therefrom, the specific toxicity of which has been completely removed by the action of chemical substances in such a manner that it retains efficient properties as an immunising antigen". Tetanus toxoid may occur as a simple solution of tetanus toxin or as alum-precipitated tetanus toxoid. The Addendum amends five monographs of the Pharmacopœia. The object of the alterations in some cases, namely, liniment of camphor and compound ointment of mercury, is to authorize the use of arachis oil, cottonseed oil or sesame oil in place of olive oil in making these preparations. In the case of capsicum ointment, the use is sanctioned of a simple ointment prepared with yellow soft paraffin in place of the present base which contains lard. A new formula is presented as a 
standard for tannic acid ointment. Five appendixes to the Addendum revise existing directions for as many processes ; they relate to the determination of (1) ultra-violet absorption, (2) iodine value, (3) unsaponifiable matter in fixed oils and fats, (4) alde. hydes or volatile oils, and (5) the assay of vitamin A.

\section{Biological Films}

The Gaumont British Instructional Films Bureau has recently added some interesting biological films to its already extensive collection. "Climbing Plants" portrays clearly the many different devices for climbing adopted by plants in their struggle for existence, including 'scramblers', thorn, petiole and aerial root climbers, as well as types that climb by means of tendrils and stems. The photographs of circumnutation in the bean seedling are as excellent as the rest of the film. In "The Swan", the photographer has captured some entertaining 'shots' of the famous swannery at Abbotsbury, near Weymouth. Courtship and breeding are carefully presented, as well as pleasant recordings of cygnet development. "The Life-Story of a Fern" includes photographs of royal, hart's-tongue, male and bracken ferns, indicating methods of spore production and liberation. In this film some informative pictures of fertilization processes in the ferns are particularly noteworthy.

"The Emperor Moth" describes the complete lifecycle of the insect from the egg to the emergence from the pupal case. The value of this film, as of many other insect films, is that the activities and development of the insect over a period of weeks may be seen as a coherent picture within a few minutes. In "Marshland Birds" various island builders like the dabchick, great crested grebe, the coot, swan and moorhen are seen in various stages of their life-history, as also are shore-builders such as the snipe, wild duck, bittern, yellow wagtail, bearded tit, reed warbler and heron. Photographs of predators like the short-eared owl and the harrier are included in order to introduce an ecological concept. In this film the photographer has secured many pictures which must be ranked well outside the usual. The appearance of these five films bears witness to the continued technical progress that is being made in the production of biological films.

\section{Observation of Chimpanzees}

AN experimental laboratory for the observation of behavioural development and adjustment, growth and maturation of chimpanzees has recently been established at the Yale Laboratories of Primate Biology, Orange Park, Florida. Infants are to be separated from their mothers at birth and reared under controlled conditions as subjects of a special research by Dr. Henry W. Nissen, assistant director. Up to March 1940, Prof. R. M. Yerkes records (Science, 91 ; April 5, 1940), 34 infants have been born in the colony, which contains 27 individuals of known birth-date and recorded life-history out of a total population of 47, ranging in age from four days to twenty-seven years. Several of these chimpanzees have resided in the colony for 8-14 years. Though the normal life of this great ape in captivity has not been determined, it is indicated that the reproductive life may exceed thirty years, while probably in favourable conditions the individual may live for fifty years. The average interval between generations in the breeding colony is almost exactly nine years.

With regard to the special problems of behaviour, it may be noted that of two primiparous mothers, neither accepted nor cared for their infants at birth. Each behaved as if surprised and bewildered, while lacking suitable, ready-to-hand patterns of behaviour for the novel emergency. Nor did either consume the afterbirth. By contrast, multiparous mothers usually eat at least part of the afterbirth and almost invariably treat the new-born infant as a familiar object, handling it skilfully and ensuring its welfare. The structurally determined maternal behaviour of the primiparous chimpanzee is importantly supplemented by acquisitions resulting from individual reproductive experience and also by social tradition.

\section{Control of Weeds and Grassland Experimentation}

THe Imperial Bureau of Pastures and Forage Crops, Aberystwyth, has recently published three new bulletins. No. 27, "The Control of Weeds" (7s. 6d.), is a symposium dealing with the various aspects of the problem as it occurs in different parts of the world, particularly in the British Commonwealth and the United States. Increasing attention is being paid to this question; extensive research work on cultural, chemical and biological means of control is in progress, and important results are already available. The practices characteristic of each country make interesting comparison. The outlook regarding chemical measures of control, for example, is very different in the United States and Germany, stress being laid on the value of cultural methods in the latter case. In Australia and New Zealand biological means have been used, with spectacular success in the eradication of prickly pear in Australia. Poisonous weeds are the subject of an article from South Africa, while Canada's contribution is chiefly ecological.

Bulletin No. $28(2 s .6 d$.$) describes the "Technique$ of Grassland Experimentation in Scandinavia and Finland". This includes both the technique for the quantitative measurement of grass production and that of stock-grazing trials. The methods of grassland analysis are chiefly contributed from Denmark and Sweden, while the grazing experiments described were carried out in Norway and Finland. Bulletin No. 29 (5s.) is entitled "Grassland Investigations in Australia". This publication may be regarded as a continuation of Bulletin No. 14 issued in 1934, which dealt with a similar subject. The enormous variation in climate naturally raises very diverse problems in the different parts of the country, but in general the pasture investigations cover two main features, natural pasture maintenance and regeneration, and the treatment of sown pastures, together with the problems of the winter and summer rainfall zones. 